\title{
Decomposition Mechanisms of Nitrogen Rich Pyrotechnics, DHT, DIAT and DAAT
}

\author{
Ayşegül Gümüş, Rıdvan Uygur and Selçuk Gümüş* \\ Yuzuncu Yil University, Faculty of Science, Department of Chemistry, 65080, Van, Turkey \\ Email: gumuss@gmail.com
}

\begin{abstract}
The decomposition mechanism of nitrogen rich, environmentally friendly (green) pyrotechnics DHT (3,6-di(hydrazino)-1,2,4,5-tetrazine), DIAT (3,6-diazido-1,2,4,5-tetrazine) and DAAT (3,3-Azobis (6-amino-1,2,4,5-tetrazine) were investigated theoretically at the level of MP2/6$31 \mathrm{G}(\mathrm{d}, \mathrm{p})$ level. The reaction coordinates for the decomposition were drawn and energy profile was built for all three. The decomposition products of these pyrotechnics are mainly nitrogen gas together with small carbon containing fragments. The reactants, intermediates, products were computed to be minima at the potential energy surface, on the other hand, the transition states were located on saddle points on the corresponding reactions.
\end{abstract}

Keywords: DHT, DIAT, DAAT, decomposition, transition states

\section{Introduction}

Primary explosives are ubiquitous and essential components of a host of military munitions as well as commercial mining, construction, and demolition applications. Since their inception, the most widely used primary explosives have been based on either lead or mercury, with lead azide and lead styphnate now making up the bulk of practical use. The high toxicity of lead compounds, along with the ever increasing environmental regulations associated with them, has led to an urgent need for environmental and cost-effective replacements that meet performance requirements [1].

Nitrogen-rich heterocyclic compounds are promising candidates for high-energy density molecules (HEDMs) together with being clean for environment. The general expectations for the potential candidates of HEDMs include high positive formation enthalpy $(\triangle \mathrm{Hf})$, high density, acceptable oxygen balance (OB), excellent detonation properties, and low sensitivity to external forces such as impact or friction [2-18]. To meet the ongoing demand for improved energetic materials, there is a clear need to continue to design and to develop novel HEDMs. High-nitrogen heterocyclic compounds such as tetrazole and tetrazine derivatives were proven to possess potential of being high-energy insensitive materials. Therefore, five- or six-membered nitrogen-containing heterocycles have been traditional sources of energetic materials. Triazole, tetrazole, and tetrazine derivatives have been investigated extensively as high-energy density materials (HEDMs) both theoretically and experimentally [19-24].

Tetrazines are aromatic six-membered rings with four nitrogen atoms (nitrogen content of $\mathrm{C}_{2} \mathrm{H}_{2} \mathrm{~N}_{4}$ : $68.3 \%$ ). Tetrazines have high heats of formation and high crystal densities, which are important and desirable features for energetic materials. They have three isomeric structures; 1,2,3,4-tetrazine (vtetrazine), 1,2,3,5-tetrazine (as-tetrazine), and 1,2,4,5-tetrazine (s-tetrazine). Among these compounds, as-tetrazine is rarely reported in the literature, as well as its derivatives. Most investigations on tetrazines are about s-tetrazine and its derivatives which are well known high performance energetic materials. For example, 3,6-diamino-1,2,4,5-tetrazine-1,4-dioxide (LAX-112), is very famous and even considered to be a prospective replacement of RDX [25].

The decomposition mechanisms of explosives are very important to understand their complicated behaviors, to control their risk during usage and storage, and to develop new high-energy materials. In this study, the decomposition mechanisms of three tetrazine derivatives (Figure 1) have been considered, theoretically. 

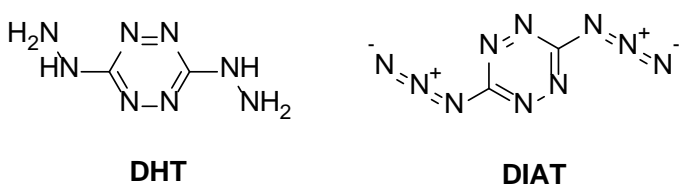

DIAT

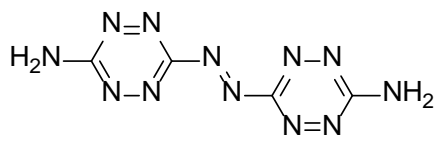

DAAT

Figure 1. The structures of DHT, DIAT and DAAT

DHT, 3,6-dihydrazino-1,2,4,5-tetrazine, is one of the most promising materials for smokeless colored pyrotechnics, which has been known for about five decades. Marcus and Remanick reported the synthesis of DHT through hydrazinolysis to 3,6-diaminotetrazine, in 1963 [26]. The thermal decomposition of DHT has been extensively investigated experimentally $[27,28]$.

DIAT, 3,6-diazido-1,2,4,5-tetrazine, is a derivative of DHT that is produced by treating DHT with nitrous acid [29]. It is considered to be an ideal potential candidate for initial explosives because of its high energy and clean and thermodynamically favorable decomposition, which extrude nitrogen gas, carbon nitrides, and carbon nanoparticles as the products under detonation [30].

DAAT, 3,3-Azobis(6-amino-1,2,4,5-tetrazine) has a high heat of formation $(+1035 \mathrm{~kJ} / \mathrm{mol})$ and it exhibits a graphitelike structure, giving an extremely high density of $1.76 \mathrm{~g} / \mathrm{cm}^{3}$.

\section{Method of Calculation}

The reactant structures, intermediates, transition sates and products were investigated using the hybrid functional B3LYP as implemented in the Gaussian 09 package program [31]. All of the structures were optimized at MP2/6-31G(d,p) level of theory followed by initial geometry optimization at B3LYP/6$31 \mathrm{G}(\mathrm{d}, \mathrm{p})$ of the reactants.

Frequency calculations were performed on the optimized structures at the same level of computational method to verify the correctness of the stationary points and the transition states as well. The vibrational analysis for each reactant did not yield any imaginary frequencies, which indicates that the structure of each molecule has at least a local minimum on the potential energy surface. The normal mode analysis was performed for $3 \mathrm{~N}-6$ vibrational degrees of freedom, $\mathrm{N}$ being the number of atoms in the structure of the corresponding compounds. On the other hand, the vibrational analysis of transition states should yield one imaginary frequency for initial proof of the transition state. Moreover, intrinsic reaction coordinate (IRC) calculations were performed on the optimized transition state geometries to verify that these connected to the given initial reaction complexes and products.

\section{$3 \quad$ Results and Discussion}

Pyrotechnics offer multifaceted technical applications, such as airbags, fire extinguishers, (road) flares, matches, the production of nanoporous foams and propellants. The development and investigation of these chemicals is part of the rapidly expanding scientific field of energetic materials. Novel developments in pyrotechnics focus on the use of nitrogen-rich compounds. In contrast to conventional energetic materials, this class of substances gain its energy from their high heats of formation rather than oxidation of a carbon backbone or a fuel. These high-energy-density materials can serve as potential propellants, coloring agents, and fuels. The derivatives of tetrazoles and tetrazines, being nitrogen-rich energetic materials, are considered to replace the traditional pyrotechnic compositions. Nitrogen-rich materials, without heavy metals and perchlorates are gaining importance as pyrothechnics due to the exhaust of green oxidation products, deeper colour and smokeless flames. The investigation of $\mathrm{Cu}$ use instead of heavy metals to produce green flame has been still going on.

The aim of this work was to investigate the decomposition mechanism of nitrogen rich, environmentally friendly (green) pyrotechnics DHT (3,6-di(hydrazino)-1,2,4,5-tetrazine), DIAT (3,6diazido-1,2,4,5-tetrazine) and DAAT (3,3-Azobis (6-amino-1,2,4,5-tetrazine), theoretically. Investigation of decomposition mechanism of DHT, DIAT and DAAT is important in terms of determination of the decomposition products and the route followed. As stated before, it is very important to investigate the 
decomposition mechanisms of explosives and understand their complicated behaviors, to control their risk during usage and storage, and to develop new high-energy materials.

The geometry optimized structures of the compounds under present consideration are given in Figure 2 .

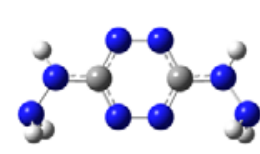

DHT

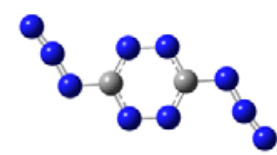

DIAT

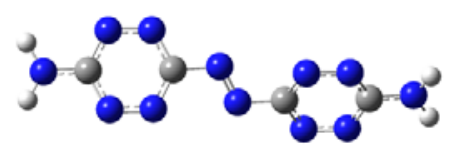

DAAT

Figure 2. Geometry optimized structures of the three tetrazine derivatives.

\subsection{Decomposition of DHT}

DHT, 3,6-di(hydrazino)-1,2,4,5-tetrazine, is considered to be a green pyrotechnic due to its high nitrogen content by mass (Figure 2). The decomposition products of DHT were reported by Oxley et.al. as two molecules of $\mathrm{NH}_{2} \mathrm{NHCN}$ fragment and one molecule of $\mathrm{N}_{2}$ gas [27]. However, the energetics of the decomposition and the transition state geometries yet reported. The decompotion of DHT may probably start by the breaking of one of the $\mathrm{C}-\mathrm{N}$ bonds forming the main tetrazine ring of the molecule. Therefore, the cleavage of that bond was perfomed upon enlengthening of it through scan keyword application in Gaussian.

In Figure 3, the reaction coordinate for the decomposition of DHT has been given. The activation energy for the initiation of decomposition was computed to be $243.0 \mathrm{~kJ} / \mathrm{mol}$, which implied an insensitive behavior at room temperature. As we were expecting the homolytic cleavage of the C-N bond to produce a biradicalic intermediate, it was observed that, $\mathrm{N}_{2}$ release took place in just one step. Moreover, the geometry optimization of the remaining part after $\mathrm{N}_{2}$ release, resulted in directly a conversion into the expected products of the experimental studies through an exothermic reaction. The vibrational analysis at the point of transition state yielded only one imaginary frequency. Observation of just one imaginary frequency is a clear indication of correct transition state however, it should be further confirmed by simulation of the corresponding frequency. Therefore, the transition state vibrational frequency (-192.4) was simulated and vibrations on the reaction center was observed (Figure $3)$.

\subsection{Decomposition of DIAT}

DIAT, 3,6-diazido-1,2,4,5-tetrazine, (see Figure 2 for optimized geometry) is another green pyrotechnic composed of mainly nitrogen atom $(85.4 \% \mathrm{~N}$ by mass). It can be synthesized form DHT upon treatment with nitrous acid [32]. The first step during the decomposition of DIAT was ring opening by C-N bond cleavage as in the case of DHT.

Removal of $\mathrm{N}_{2}$ was observed in one step, after starting the ring opening process. The geometry optmization of the transition state geometry structure resulted in a fragmentation of the compound from N-N bond. Then, a second molecule of as removed from the remaining fragments which required only $71.2 \mathrm{~kJ} / \mathrm{mol}$ of energy of activation. That is, after the first exhaust of $\mathrm{N}_{2}$ gas, the molecule immediately continued decomposition by the extraction of the second molecule $\mathrm{N}_{2}$ without any need for further primary initiators. The first and second transition states were labeled by -157 and -401 values of 
imaginary frequencies, respectively. The simulation of these frequencies at the reaction centers proved the correctness of them (Figure 4).

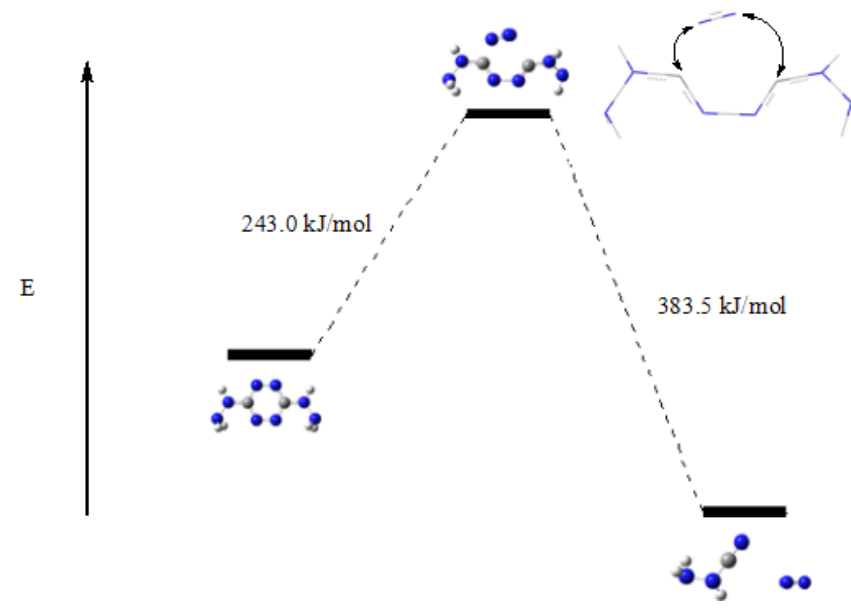

Figure 3. The decomposition reaction coordinate for DHT

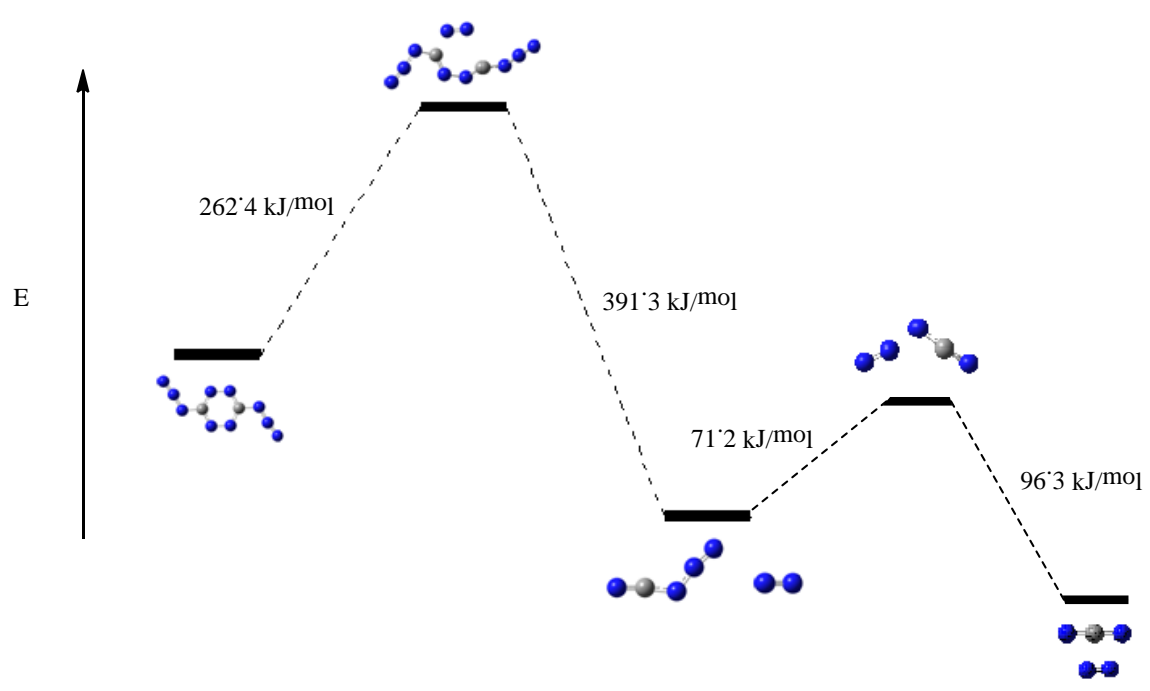

Figure 4. The decomposition reaction coordinate for DIAT.

\subsection{Decomposition of DAAT}

DAAT, 3,3-Azobis(6-amino-1,2,4,5-tetrazine), is another pyrotechnic providing green chemistry products and requirements of preferable energetic material. It is composed of two tetrazine rings. The ring opening at one of the tetrazine rings was ended up with the removal of the first $\mathrm{N}_{2}$ from the parent compound. The geometry optimization followed by the first $\mathrm{N}_{2}$ exhaust again resulted in the homolytic bond cleavage of the N-N bond. Thereafter, the second tetrazine ring was decomposed by the removal of the $\mathrm{N}_{2}$ gas. The N-N bond cleavage took place upon geometry optimization again to obtain energetically more favorable intermadiates, one of which $(\mathrm{NC}-\mathrm{NN}-\mathrm{CN})$ further decomposed to give the final products (Figure 5). 
The overall decomposition process passed from three transition states, and a total of three molecules of $\mathrm{N}_{2}$ were exhausted. The transtion states were located by absolutely high values of imaginary frequencies.

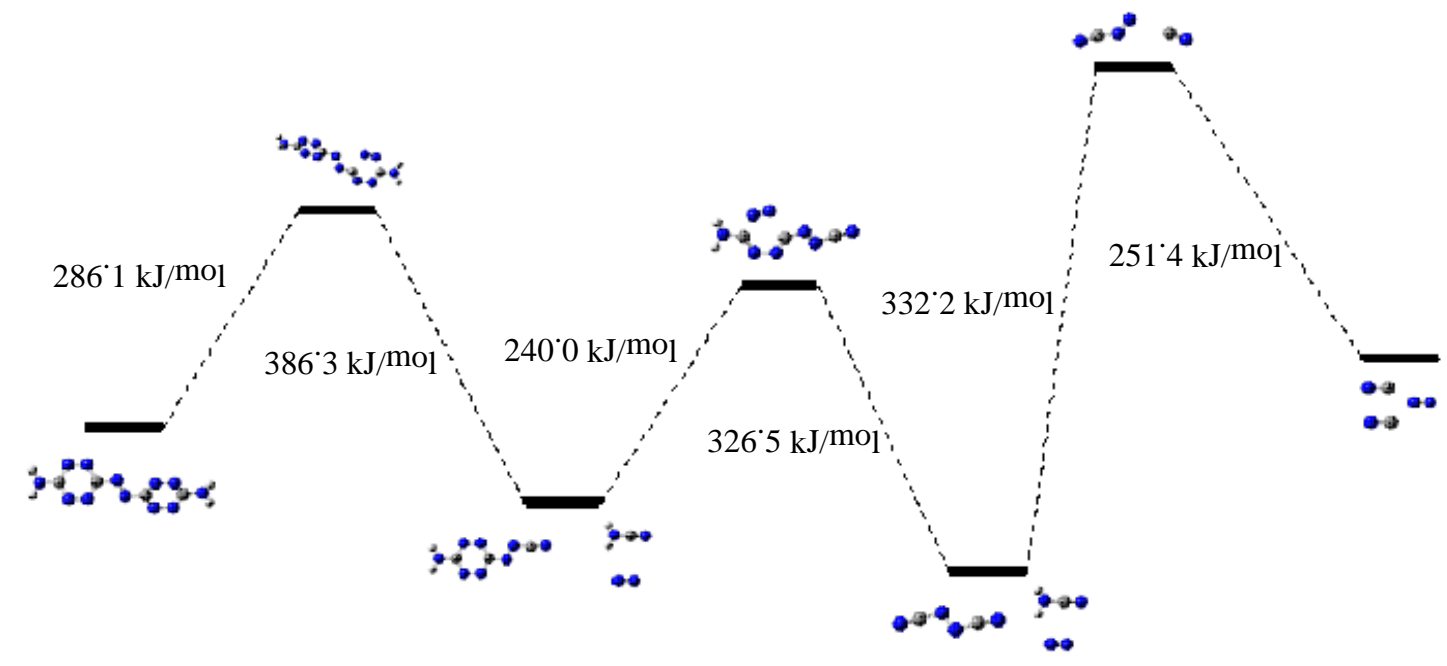

Figure 5. The decomposition reaction coordinate for DIAT.

\section{Conclusion}

In conclusion, the decomposition mechanisms of nitrogen rich, environmentally friendly (green) pyrotechnics DHT (3,6-di(hydrazino)-1,2,4,5-tetrazine), DIAT (3,6-diazido-1,2,4,5-tetrazine) and DAAT (3,3-Azobis (6-amino-1,2,4,5-tetrazine) were investigated theoretically at the level of MP2/6-31G(d,p) level of theory. Research of decomposition mechanisms of DHT, DIAT and DAAT is important in terms of determination of the decomposition products and the route followed. Moreover, investigation of the decomposition mechanisms of explosives and understand their complicated behaviors are vital importance in order to control their risk during usage and storage, and to develop new high-energy materials.

The reaction coordinates for the decomposition mechanisms of three important pyrotechnics were computed and drawn. The transition states and intermadiates were located throughout the coordinate. The energy profile of the pyrotechnics under consideration revealed that all of the compounds are stable at room temperature and need an initiator or heat to decompose.

Acknowledgments. We are grateful to the Scientific and Technological Research Council of Turkey (TUBITAK) for the grant (No. 214Z239).

\section{References}

1. T. Brinck and K.D. Oyler, Green Primary Explosives, KTH Royal Institute of Technology, Sweden, 2014.

2. L.E. Fried, M.R. Manaa, P.F. Pagoria, and R.L. Simpson, "Design and Synthesis of Energetic Materials," Annu. Rev. Mater. Res. vol. 31, pp. 291-321, 2001.

3. L. Qiu, W.H. Zhu, J.J. Xiao, W. Zhu, H.M. Xiao, H. Huang, and J.S. Li, "Molecular dynamics simulations of trans-1,4,5,8-tetranitro-1,4,5,8-tetraazadecalin-based polymer-bonded explosives," J. Phys. Chem. B, vol. 111, pp. 1559-1566, 2007.

4. X.J. Xu, W.H. Zhu, and H.M. Xiao, "DFT Studies on the Four Polymorphs of Crystalline CL-20 and the Influences of Hydrostatic Pressure on E-CL-20 Crystal," J. Phys. Chem. B, vol. 111, pp. 2090-2097, 2007. 
5. L. Turker, and S. Varis, "A Review Of Polycyclic Aromatic Energetic Materials," Polycycl. Aromat. Compd. vol. 29, pp. 228-266, 2009.

6. Y.H. Joo, and J. M. Shreeve, "Energetic mono-, di-, and tri-substituted nitroiminotetrazoles," Angew. Chem. Int. Ed. vol. 48, pp. 564-567, 2009.

7. T. Wei, W.H. Zhu, X.W. Zhang, Y.F. Li, and H.M. Xiao, "Molecular design of 1,2,4,5-tetrazine-based high-energy density materials," J. Phys. Chem. A, vol. 113, pp. 9404-9412, 2009.

8. M.B. Talawar, R. Sivabalan, T. Mukundan, H. Muthurajan, A.K. Sikder, B.R. Gandhe, and A.S. Rao, "Environmentally compatible next generation green energetic materials (GEMs)," J. Hazard. Mater. vol. 161, pp. 589-607, 2009.

9. P. Ravi, G.M. Gore, S.P. Tewari, and A.K. Sikder, "Quantum chemical studies on the fused nitroazoles," J. Mol. Struct. (THEOCHEM) vol. 955, pp. 171-177, 2010.

10. T.M. Klapötke and G. Steinhauser, "“Green" Pyrotechnics: A Chemists' Challenge," Angew. Chem. Int. Ed. vol. 47, pp. 3330-3347, 2008.

11. X.W. Zhang, W.H. Zhu, T. Wei, C.C. Zhang, and H.M. Xiao, "Densities, Heats of Formation, Energetic Properties, and Thermodynamics of Formation of Energetic Nitrogen-Rich Salts Containing Substituted Protonated and Methylated Tetrazole Cations: A Computational Study," J. Phys. Chem. C, vol. 114, pp. 1314213152, 2010.

12. T. Wei, J.J. Zhang, W.H. Zhu, X.W. Zhang, and H.M. Xiao, "A comparison of high-level theoretical methods to predict the heats of formation of azo compounds," J. Mol. Struct. (THEOCHEM) vol. 956, pp. 55-60, 2010.

13. X.W. Zhang, W.H. Zhu, and H.M. Xiao, "Theoretical studies on heats of formation, detonation properties, and bond dissociation energies of monofurazan derivatives," Int. J. Quantum. Chem. vol. 110, pp. 1549-1558, 2010.

14. W.H. Zhu, C.C. Zhang, T. Wei, and H.M. Xiao, "Theoretical studies of furoxan-based energetic nitrogen-rich compounds," Struct. Chem. vol. 22, pp. 149-159, 2011.

15. T.M. Klapötke, F.A. Martin, and J. Stierstorfer, "C2N14 - A new energetic and highly sensitive binary azidotetrazole," Angew. Chem. Int. Ed. vol. 50, pp. 4227-4229, 2011.

16. P. Ravi, G.M. Gore, S.P. Tewari, and A.K. Sikder, "Quantum Chemical Studies On The Structure And Detonation Properties Of The Fused Polynitrodiazoles: New High Energy Density Molecules," Int. J. Quantum. Chem. vol. 111, pp. 4352-4362, 2011.

17. W.H. Zhu, Q.L. Yan, J.S. Li, B.B. Cheng, Y.L. Shao, X.L. Xia, and H.M. Xiao, "Prediction of the properties and thermodynamics of formation for energetic nitrogen-rich salts composed of triaminoguanidinium cation and 5-nitroiminotetrazolate-based anions," J. Comput. Chem. vol. 33, pp. 1781-1789, 2012.

18. T. Wei, J.Z. Wu, C.C. Zhang, W.H. Zhu, and H.M. Xiao, "Characterization of nitrogen-bridged 1,2,4,5tetrazine-, furazan-, and $1 H$-tetrazole-based polyheterocyclic compounds: heats of formation, thermal stability, and detonation properties," J. Mol. Model. vol. 18, pp. 3467-3479, 2012.

19. J. Neutz, O. Grosshardt, S. Schaufele, H. Schuppler, and W. Schweikert, "Synthesis, characterization and thermal behaviour of guanidinium-5-aminotetrazolate (GA)-a new nitrogen-rich compound," Propellants Explos. Pyrotech. vol. 28, pp. 181-188, 2003.

20. J.A. Ciezak, and S.F. Trevino, "The inelastic neutron scattering spectra of 3-amino- 5-nitro-1,2,4-2H-triazole: experiment and DFT calculations," Chem. Phys. Lett. vol. 403, pp. 329-333, 2005.

21. M.H.V. Huynh, M.A. Hiskey, C.J. Pollard, D.P. Montoya, E.L. Hartline, and R.D. Gilardi, "4,4',6,6'-Tetrasubstituted hydrazo- and azo-1,3,5-triazines," J. Energ. Mater. vol. 22, pp. 217-229, 2004.

22. M.H.V. Huynh, M.A. Hiskey, D.E. Chavez, D.L. Naud, and R.D. Gilardi, "Synthesis, characterization, and energetic properties of diazido heteroaromatic high-nitrogen C-N compound," J. Am. Chem. Soc. vol. 127, pp. 12537-12543, 2005.

23. K.E. Gutowski, R.D. Rogers, and D.A. Dixon, "Accurate thermochemical properties for energetic materials applications. II. Heats of formation of imidazolium-, 1,2,4-triazolium, and tetrazolium-based energetic salts from isodesmic and lattice energy calculations," J. Phys. Chem. B, vol. 111, pp. 4788-4800, 2007.

24. M.B. Talawar, R. Sivabalan, N. Senthilkumar, G. Prabhu, and S.N. Asthana, "Synthesis, characterization and thermal studies on furazan- and tetrazine-based high energy materials," J. Hazard. Mater. vol. 113, pp. 11-25, 2004.

25. T. Wei, W. Zhu, X. Zhang, Y. Li, and H. Xiu, "Molecular design of 1,2,4,5-tetrazine-based high-energy density materials," J Phys Chem A, vol. 113, pp. 9404-9412, 2009. 
26. H. J. Marcus, and A. Remanick, "The Reaction of Hydrazine with 3,6-Diamino-s-tetrazine," J. Org. Chem. vol. 28, pp. 2372-2375, 1963.

27. J. C. Oxley, J. L. Smith, and H. Chen, "Thermal decomposition of high-nitrogen energetic compounds Dihydrazido-S-tetrazine salts," Thermochimica Acta, vol. 384, pp. 91-99, 2002.

28. V.P. Sinditskii, V.Yu. Egorshev, G.F. Rudakov, A.V. Burzhava, S.A. Filatov, and L.D. Sang, "Thermal behavior and combustion mechanism of high-nitrogen energetic materials DHT and BTATz," Thermochimica Acta, vol. 535, pp. 48-57, 2012.

29. M. Friedrich, J. C. Gulvez-Ruiz, T. M. Klapötke, P. Mayer, and B. Weber, J. J. Weigand, "BTA Copper Complexes," Inorg. Chem. vol. 44, pp. $8044-8052,2005$.

30. Q. Wu, W. Zhu, and H. Xiao, "An ab initio molecular dynamics study of thermal decomposition of 3,6di(azido)-1,2,4,5-tetrazine," Phys.Chem.Chem.Phys., vol. 16, pp. 21620-21628, 2014.

31. Frisch, M. J.; Trucks, G. W.; Schlegel, H. B.; Scuseria, G. E.; Robb, M. A.; Cheeseman, J. R.; Scalmani, G.; Barone, V.; Mennucci, B.; Petersson, G. A.; et al. Gaussian 09; Wallingford, CT, Gaussian Inc., 2009.

32. D.E. Chavez, M.A. Hiskey, M.H. Huynh, D.L. Naud, S.F. Son, and B.C. Tappan, "The combustion properties of novel high-nitrogen energetic materials," J Pyrotechnics, vol. 23, pp. 70-80, 2006. 